Ensino, Saúde e Ambiente - v. 14 n. esp. (2021): Dossiê Paulo Freire para além dos 100 anos:

construir utopias, transformar a realidade, p. 79-94.

As Epistemologias Freireanas

ENSINO, SAÚDE E AMBIENTE

\title{
Revisitar Paulo Freire em busca da ternura
}

\section{Revisit Paulo Freire in search of tenderness}

\section{Dulcinéia de Fátima Ferreira ${ }^{1}$}

1 Pós doc em Cultura Popular, Universidade Federal do Maranhão (UFMA), São Luís, Maranhão, Brasil dulceciranda2@gmail.com /http://orcid.org/0000-0001-5654-0098

\section{Palavras-chave:} Paulo Freire; ternura; educação popular; processo de subjetivação; educação como prática da liberdade

\section{Keywords:}

Paulo Freire; tenderness; popular education; subjectivation process; education as a practice of freedom
RESUMO: Este artigo é fruto do pensamento em movimento. Um exercício de vasculhar o vivido, o estudado em busca da criação de um conhecimento que possa nos auxiliar na lida do dia a dia diante dos desafios do viver, caminhamos em busca da ternura. Debruçamo-nos sobre cenário sombrio da história que atravessamos. Destacamos o sofrimento causado pela pandemia e pela política necrófila instalada em nosso país desde 2018 e a forma como o contexto marca a vida das pessoas, ao ponto de muitas pessoas estarem à beira da exasperação. São diversas frentes de luta pelo direito à vida. Neste estudo tomamos como análise a política de subjetivação em curso que tenta nos produzir como impotentes, inferiores e insignificantes. Tenta controlar e sufocar nossa existência. Reafirmamos que nosso desejo é viver uma vida digna, uma vida boa, com motivos para festejar. Procuramos um abrigo, um lugar simples em que possamos nos banhar, nos alimentar, descansar e festejar. Vasculhamos o vivido em busca da ternura, então revisitamos Paulo Freire por acreditarmos que o modo como ele disponibilizou suas palavras, sua filosofia, nos possibilita a educação como prática da liberdade. Deste modo a educação popular constitui-se como uma experiência de ternura.

ABSTRACT: This article is the result of thinking in motion. An exercise in digging through the lived, the studied in the search of knowledge creation that can help us deal with the daily challenges of living, we walk searching tenderness. We focus on the dark scenario of the story we are going through. We highlight the suffering caused by the pandemic and the necrophilic policy installed in our country since 2018 and the way in which the context marks people's lives, to the point that many people are on the verge of exasperation. There are several sides in the fight fot the right to life. In this study, we take as analysis the ongoing policy of subjectivation that tries to produce us as powerless, inferior and insignificant. It tries to control and suffocate our existence. We reaffirm that our desire is to live a dignified life, a good life, with reasons to celebrate. We look for shelter, a simple place where we can bathe, feed, rest and celebrate. We dug through the lived in search of tenderness, so we revisited Paulo Freire because we believe that the way in which he made his words and philosophy available, enables education as a practice of freedom. In this way, popular education is an experience of tenderness. 
Ensino, Saúde e Ambiente - v. 14 n. esp. (2021): Dossiê Paulo Freire para além dos 100 anos: construir utopias, transformar a realidade, p. 79-94.

\title{
As Epistemologias Freireanas
}

\section{PRIMEIRAS PALAVRAS...}

\author{
Peço licença para algumas coisas \\ primeiramente para desfraldar \\ este canto de amor publicamente \\ sucede que só sei dizer amor \\ quando reparto o ramo azul de estrelas \\ que em meu peito floresce de menino. \\ Thiago de Mello (2002, p. 116)
}

Inspirada em Thiago de Mello, peço licença para compartilhar uma experiência vivenciada nos encontros que vivi e vivo com Paulo Freire. Mobilizada por suas palavras sigo levando um ramo azul de estrelas, iluminando os caminhos da escuridão deste viver. Vou assim tecendo aproximações com os leitores e as leitoras.... Que sintam-se acolhidos e acolhidas.

Antes de contar o fato que me levou a escrever, preciso dizer que este texto foi escrito em um período muito doloroso da nossa história. Estamos no meio de uma pandemia causada pelo coronavírus, no momento em que escrevo já são mais de 560 mil mortes. Um temporal revoltoso. Nunca havíamos vivido algo semelhante. Sofremos de forma avassaladora as consequências da necropolítica (MBEMBE, 2020) instalada no Brasil desde 2018.

Este contexto tem nos forçado a reinventar a forma de viver. Um chamado a recriar o modo de estar na educação e no mundo. Neste cenário turbulento a universidade é convocada a experienciar um deslocamento no modo de lidar, pensar e criar conhecimento. Mais que nunca é preciso investir energias humanas na produção de um "conhecimento prudente para uma vida decente" (SANTOS, 2004), um modo de lidar com o conhecimento que contribua para a criação uma política biófila, uma política em defesa da vida capaz de estancar o veneno que a necropolítica espalha pelo nosso país desde 2016 com o golpe.

Afetada pelo sofrimento que esta política nefasta, em especial neste tempo pandêmico, tem produzido em nós, revisitamos Paulo Freire em busca da ternura. "A ternura é o caminho que percorremos quando nos damos conta da falibilidade humanas, da proximidade do ódio e da facilidade com que nos convertemos em sujeitos que maltratam”. (RESTREPO, 2000, p.63). Procuramos um abrigo, um lugar simples em que possamos nos banhar, nos alimentar e descansar.

Marcada por este tempo escrevo como quem esperança, esperança do verbo esperançar que Freire nos convidou a criar. "Enquanto necessidade ontológica a esperança precisa da prática para tornar-se concretude histórica. É por isso que não há esperança na pura espera, nem tampouco se alcança o que se espera na espera pura, que vira assim uma espera vã.” 
Ensino, Saúde e Ambiente - v. 14 n. esp. (2021): Dossiê Paulo Freire para além dos 100 anos: construir utopias, transformar a realidade, p. 79-94.

\section{As Epistemologias Freireanas}

(FREIRE, 1992, p. 11). Esperanço com estas palavras. Espero que tu esperances também, de modo que todes ${ }^{1}$ possamos seguir esperançando, teimando em seguir vivendo com alegria no coração, teimando em acreditar na humanidade e na nossa capacidade de amar, de sermos ternos uns com os outros, que possamos atuar no mundo a partir do princípio do bem viver. “Apesar de reconhecermos a extrema dificuldade para se construir o Bem Viver em comunidades imersas no turbilhão do capitalismo, acredita- se que há muitas possibilidades de começar a praticá-lo" (ACOSTA, 2016, n.p.). Sabemos das dificuldades para nos deslocarmos do modo de viver capitalista impregnado em nós.

A mudança de paradigma, só se dará quando mudarmos em princípio nossa subjetividade colonial. Ajustar as lentes com as quais observamos, entendermos e elaboramos a realidade, compreender a cosmovisão dos povos originários, buscar o olhar desses povos, o entendimento e como vivem no mundo, é um importante passo em direção a essa re-configuração de nossas meta-formas em desassossego. (OLIVEIRA, 2020, p. 51)

É preciso travar uma luta conosco para que possamos nos abrir para encontros com outros modos de viver, para aprendermos com as culturas tradicionais afro-ameríndias, culturas cujos valores civilizatórios ancoram se na solidariedade, na circularidade, no comunitarismo, no bem viver. Acredito que para isso precisamos tratar o analfabetismo afetivo que nos aflige e tem gerado tantas formas de violência, afinal (...)

(...). Nós cidadãos ocidentais sofremos uma terrível deformação, um pavoroso empobrecimento histórico que nos levou a um nível jamais conhecido de analfabetismos afetivo. (...) padecemos de um analfabetismo afetivo que dificulta compreender as raízes de nosso sofrimento. Analfabetismo que nos impede de

\footnotetext{
1 "Me lembro como se fosse agora que estivesse lendo as duas ou três primeiras cartas que recebi, de como, condicionado pela ideologia autoritária, machista, reagi. E é importante salientar que, estando nos fins de 1970 e começos de 1971, eu já havia vivido intensamente a experiência da luta política, já tinha cinco a seis anos de exílio, já havia lido um mundo de obras sérias, mas, ao ler as primeiras críticas que me chegavam, ainda me disse ou me repeti o ensinado na minha meninice: "Ora, quando falo homem, a mulher necessariamente está incluída. " Em certo momento de minhas tentativas, puramente ideológicas, de justificar a mim mesmo, a linguagem machista que usava, percebi a mentira ou a ocultação da verdade que havia na afirmação: "Quando falo homem, a mulher está incluída. " E por que os homens não se acham incluídos quando dizemos: "As mulheres estão decididas a mudar o mundo. "? Nenhum homem se acharia incluído no discurso de nenhum orador ou no texto de nenhum autor que escrevesse: "As mulheres estão decididas a mudar o mundo." Da mesma forma como se espantam (os homens) quando a um auditório quase totalmente feminino, com dois ou três homens apenas, digo: "Todas vocês deveriam" etc. Para os homens presentes ou eu não conheço a sintaxe da língua portuguesa ou estou procurando "brincar" com eles. O impossível é que se pensem incluídos no meu discurso. Como explicar, a não ser ideologicamente, a regra segundo a qual se há duzentas mulheres numa sala e só um homem devo dizer: "Eles todos são trabalhadores e dedicados? " Isto não é, na verdade, um problema gramatical, mas ideológico. (...). Daquela data até hoje me refiro sempre a mulher e homem ou seres humanos. Prefiro, às vezes, enfear a frase explicitando, contudo, minha recusa à linguagem machista. (FREIRE, 1992, p. 67-68)
} 
Ensino, Saúde e Ambiente - v. 14 n. esp. (2021): Dossiê Paulo Freire para além dos 100 anos: construir utopias, transformar a realidade, p. 79-94.

\section{As Epistemologias Freireanas}

encontrar chaves para melhorar nossa vida cotidiana. Basta lançar um olhar à família para dar-nos conta do montante de sofrimento que carregamos e constatar que aquilo que por definição deveria ser um ninho de amor se converte frequentemente em foco de violência. (RESTREPO, 2000, p. 19-20)

Revisitamos Paulo Freire e neste encontro somos acolhides por suas palavras e seu modo de viver como uma "obra de arte que permanece" (PEREIRA, 2014) que continua nos inspirando. Aquele desespero e a falta de orientação são tratados, ao serem escutados, problematizados vão sendo analisados compreendidos e abrem possibilidades para nascentes do devir.

Revisito Freire sabendo que juntes encontraremos outros tantos que marcham ${ }^{2}$ contra a fome, a miséria, o abandono da vida, a servidão, as fake news, o racismo, homofobia, machismo, feminicídios, enfim contra toda forma de servidão e de diminuição da vida.

Marchamos, pois afinal...

Se é possível obter água cavando o chão, se é possível enfeitar a casa, se é possível crer desta ou daquela forma, se é possível nos defender do frio ou do calor, se é possível desviar leitos de rios, fazer barragens, se é possível mudar o mundo que não fizemos, o da natureza, porque não mudar o mundo que fazemos, o da cultura, o da história, o da política? (FREIRE, 2000, 98)

Saímos em marcha resistindo ao apagamento das nossas vidas, como quem ao lutar festeja, celebra a força do viver com, do conviver. Como quem sente na carne que o lutar e o festejar se completam se retroalimentam, pois é no coletivo, no viver em comunidade que podemos aprender a pensar, criar e viver o comum, o bem viver.

Marchamos como quem canta enquanto quem tecendo rede tece a vida, como quem dança, quem brinca e resiste ao apagamento das vidas pobres, pretas, indígenas, homossexuais, mulheres, como quem teima e resiste ao apagamento das culturas populares seguindo o batalhão do bumba meu boi do maranhão, virando noites e dias cumprindo sua obrigação ao mesmo tempo em que tece motivos para o viver se alimenta da alegria e amorosidade.

Marchamos, pois sentimos na carne a urgência de "racharmos as palavras e as coisas" (DELEUZE, 1992) que querem nos aprisionar, nos impedir de criar caminhos para que possamos seguir desenhando "mapas para festa" (MADURO, 1994).

Ao revisitarmos Freire desejamos viver a vida em sua plenitude, afinal (...)

\footnotetext{
${ }^{2}$ Inspiro-me na última entrevista de Paulo Freire concedida em 17/04/97 quando fala sobre as marchas do MST. In: https://www.youtube.com/watch?v=U190heSRYfE\&t=242s
} 
Ensino, Saúde e Ambiente - v. 14 n. esp. (2021): Dossiê Paulo Freire para além dos 100 anos: construir utopias, transformar a realidade, p. 79-94.

\section{As Epistemologias Freireanas}

Viver a vida é, entre outras coisas (e sobretudo, quem sabe?), buscar a vida feliz e não meramente sobreviver. A vida que se reduz meramente à luta pela sobrevivência - para não morrer e mais nada - é vivida como um pesadelo, como situação desesperadora, como um mal. [...] Mas a vida que buscamos e apreciamos é aquela que sentimos como vida em abundância: vida que é possível gozar junto com os outros, sem por em perigo que outros também gozem; vida para desfrutar sem destruir a possibilidade de usufrui-la até a mais avançada idade; vida digna de celebrar em comunidade e de recordar depois com saudade... a vida boa, a vida feliz! Esta vida - a vida que vale a pena viver.

E que nos estimula a degustá-la - não se resume a uma simples luta contra a morte, mas a busca do prazer em comum, a alegria duradoura, o deleite profundo, o gozo gratuito, a felicidade que contagia. A vida boa, a vida feliz - a vida que merece ser preservada, nutrida, comunicada, reproduzida e festejada - é o desfrute compartilhado do afeto, da companhia, do trabalho, do alimento, do descanso, da arte, do jogo, da dança, ... enfim, da festa! (MADURO, 1994, p.31).

Como na Pedagogia do oprimido (FREIRE, 1987), diante da dramaticidade da hora atual colocamo-nos a nós mesmos como problemas.

Mais uma vez os homens, desafiados pela dramaticidade da hora atual, se põe a si mesmos como problema. Descobrem que pouco sabem de si, de seu "posto no cosmos", e se inquietam por saber mais. Estará, aliás, no reconhecimento do seu pouco saber de si uma das razões desta procura. Ao se instalarem na quase, senão trágica descoberta do seu pouco saber de si, se fazem problema a eles mesmos. Indagam. Respondem, e suas respostas os levam a novas perguntas. (FREIRE, 1987, p. 29)

Seguimos teimando em não acreditar que a história chegou ao final. "A História é tempo de possibilidade e não de determinações. (...) Pensar a História como possibilidade é reconhecer a educação também como possibilidade" (FREIRE, 2000a, p. 35), como possibilidade de desenhar mapas para festa.

Com o corpo encharcado do vivido escrevo estas palavras que foram gestadas na experiência de pensar e viver a educação como território de cuidado e ternura, capaz de auxiliar-nos nesta travessia do viver. 
Ensino, Saúde e Ambiente - v. 14 n. esp. (2021): Dossiê Paulo Freire para além dos 100 anos: construir utopias, transformar a realidade, p. 79-94.

As Epistemologias Freireanas

1. UM ENCONTRO DE HOSPITALIDADE COM PAULO FREIRE

Pois aqui está a minha vida. Pronta para ser usada.

Vida que não se guarda nem se esquiva, assustada. Vida sempre a serviço da vida.

Pra servir ao que vale a pena o preço do amor.

Ainda que o gesto me doa, não encolho a mão: avanço levando um ramo de sol. Mesmo enrolada em pó, dentro da noite mais fria, a vida que vai comigo é fogo: está sempre acesa.

Por isso é que agora vou assim No meu caminho. Publicamente andando.

Não, não tenho caminho novo.

$\mathrm{O}$ que tenho de novo

é o jeito de caminhar. Aprendi (o caminho me ensinou) a caminhar cantando como convém a mim e aos que vão comigo.

Pois já não vou mais sozinho. Thiago de Mello (2002, p. 97)

O meu encontro com Paulo Freire foi, e ainda é, um movimento de afetos. Quando bati, pela primeira vez em sua porta, ele não me conhecia, não sabia quem eu era, mas abriu a porta e, através da forma como preparou seu texto, as palavras que nos disponibilizou pude viver, com ele, uma experiência de hospitalidade.

Utilizo o termo "hospitalidade" inspirada no livro de Leonardo Boff: Virtudes para um outro mundo possível: Hospitalidade, direitos e deveres de todos (2005). Nesse livro, Boff narra-nos o mito da hospitalidade, no qual um casal de velhos, muito pobre, Filêmon e Báucis, hospedam Júpiter, pai-criador do céu e da terra, e seu filho Hermes (sem saber quem eram, pois estes estavam disfarçados de pobres mortais). Descrevo trechos do mito, que me afetaram por demonstrarem como a hospitalidade se dá de forma gratuita e desinteressada:

Forasteiros, vocês devem estar muito cansados e com fome. Venham, entrem em nossa casa. É pobre, mas está pronta para acolhê-los (...) Filêmom foi à horta atrás da choupana e colheu algumas folhas e legumes, enquanto Báucis tirava do alto, 
Ensino, Saúde e Ambiente - v. 14 n. esp. (2021): Dossiê Paulo Freire para além dos 100 anos: construir utopias, transformar a realidade, p. 79-94.

\section{As Epistemologias Freireanas}

onde estava dependurado numa vara, o último pedaço de toucinho que restara (...) numa panela de barro, bem antiga, cozinharam os legumes com o toucinho. Um cheiro bom de comida caseira se espalhava pela choupana a ponto de fazer salvar Júpiter e Hermes, mortos de fome (...). Queridos hóspedes, vamos comer, pois vocês o merecem depois de tantas canseiras. Perdoem a simplicidade e a pobreza da cozinha. (p. 80-81). Por fim, os dois velhinhos ofereceram sua própria cama, a única que havia na choupana. (BOFF, 2005, p. 82)

A experiência de hospitalidade vivida no encontro com Freire se deu pelas palavras. Não podemos nos esquecer "que as palavras podem ser ternas, pois, como dizia Racine, com o discurso também se pode agradar e comover - plaire et toucher - ou agredir e violentar, independentemente de sua estrutura lógicas ou das cadeias argumentais que se utilizem". (RESTREPO, 2000, p. 16).

Entre denúncias e anúncios Freire falava da busca de um outro mundo, uma outra educação, falava também de um outro jeito de viver, uma outra forma de ser e estar no mundo, das bonitezas e feiuras dos seres humanos.

Em nenhum momento esconde os conflitos, ao contrário, provoca-nos novas perguntas, questionamentos, incômodos. Desoculta nossas incertezas, nossas contradições. Em muitos momentos escancara nossa fragilidade humana. "Paulo Freire nos provoca internamente, sacudindo conformismos e nos fazendo reconhecer nossos limites: a incompletude de que somos feitos e a necessidade de recomeçar, reavaliando nossas organizações como estratégias para ir rompendo processos de submissão que nos aprisionam" (LINHARES, 2001, p. 48).

Suas palavras me afetaram. Nessa "visita" que fiz a Freire encontrei respostas para muitas inquietações e também muitas outras perguntas. Um convite para um diálogo permanente com ele, comigo, com os outros e com a vida. Logo nos primeiros encontros percebi que tratava-se de uma pessoa especial, pois através das suas palavras pude escutar as reverberações de marcas impressas em meu corpo.

(...)o que estou chamando de marca são exatamente estes estados inéditos que se produzem em nosso corpo, a partir das composições que vamos vivendo. Cada um destes estados constitui uma diferença que instaura uma abertura para a criação de um novo corpo, o que significa que as marcas são sempre gênese de um devir. (ROLNIK, 1993, p.2) 
Ensino, Saúde e Ambiente - v. 14 n. esp. (2021): Dossiê Paulo Freire para além dos 100 anos: construir utopias, transformar a realidade, p. 79-94.

\section{As Epistemologias Freireanas}

A partir dos atravessamentos vividos com as leituras vou percebendo que ele falava como quem ao falar escuta, mas a escuta não era uma escuta qualquer. Era uma escuta atenta, como quem realmente se interessava pelo meu desamparo, meu desespero, minhas aflições. Escuta, não apenas ouve. Esta percepção me possibilitou a experiência de acolhimento, de pertencimento.

Começo a compreender que " impedidos de atuar, de refletir, os homens encontram-se profundamente feridos em si mesmos" (FREIRE, 1983, p.18) e que não existem receitas nem caminhos a serem trilhados, o desafio é lançar-se nesta busca de criar e reinventar o mundo e não em repeti-lo. Afinal, "os sonhos são projetos pelos quais se luta. Sua realização não se verifica facilmente, sem obstáculos. Implica, pelo contrário, avanços, recuos, marchas às vezes demoradas. Implica luta”. (FREIRE, 2000, p. 54).

Freire foi me lembrando que em todo homem existe um ímpeto criador que nasce da sua inconclusão. (FREIRE, 1983). De frente para este ser inacabado e finito que somos Freire nos acolhe em seus textos como "gente", dialoga conosco e nos aponta o seu "ser homem", na condição também de "inconcluso" e criador.

Gosto de ser gente, (...) porque mudar o mundo é tão difícil quanto possível. É a relação entre a dificuldade e a possibilidade de mudar o mundo que coloca a questão da importância do papel da consciência na história, a questão da decisão, da opção, a questão da ética e da educação e de seus limites. (FREIRE, 2000, p. 39)

Educador político e poeta, parte da paixão pela vida, de seus incômodos com as situações miseráveis, em que vive o ser humano, não pensando apenas nos aspectos econômicos e sociais, mas também na condição da precariedade, incerteza e risco que é o viver. Convida-nos a reinventar o mundo, a vida, a educação e a escola.

(...) é vivendo, não importa se com deslizes e com incoerências, mas disposto a superá-los, a humildade, a amorosidade, a coragem, a tolerância, a competência, a capacidade de decidir, a segurança, a eticidade, a justiça, a tensão entre paciência e impaciência, a parcimônia verbal, que contribuo para criar e forjar a escola feliz, a escola alegre. A escola que é aventura, que marcha, que não tem medo do risco, por que recusa o imobilismo, a escola em que se pensa, em que se atua, em que se cria, em que se fala, em que se ama, se adivinha, a escola em que apaixonadamente diz sim à vida. E não a escola que emudece e me emudece. (FREIRE, 2000b, p,63).

Com delicadeza, palavras mansas, nos provoca desassossegos, "derruba-nos" do "pedestal de muito saber, de muito poder", mostra-nos, sem arrogância, que sabemos algo, mas não tudo, que não somos superiores ou inferiores como seres humanos, apenas diferentes. 
Ensino, Saúde e Ambiente - v. 14 n. esp. (2021): Dossiê Paulo Freire para além dos 100 anos: construir utopias, transformar a realidade, p. 79-94.

\section{As Epistemologias Freireanas}

Que "ninguém nasce feito: é experimentando-nos no mundo que nós nos fazemos" (FREIRE, 2000a, p. 79). "Desconstrói" a ideia de que o educador tudo sabe, tudo pode. Mostra-nos a necessidade de nos fazermos com mais humildade, reconhecendo nossas limitações e finitude.

Afetada pela potência deste encontro, meu modo de pensar e viver sofre deslocamentos. Com Paulo Freire descobri que existe a possibilidade de poder ser frágil, de poder ser gente, que não é, mas está sendo; que a realidade é, em parte, criação dos homens e das mulheres, e que ao mesmo tempo em que nos reinventamos no mundo vamos reinventando-o.

Que acalanto na alma saber que não preciso saber tudo, que posso assumir o meu medo, minhas fragilidades ao mesmo tempo que reconheço e reafirmo minhas potencialidades. Ao ser acolhida na morada de Freire, compreendi meu lugar no mundo.

A consciência de que faço parte da classe trabalhadora me possibilitou entender que muitas das minhas inquietações, indignações e sofrimentos eram parte dos problemas, inquietações e sofrimentos da classe trabalhadora. Esta consciência me religa, abre passagem para o sentimento de pertencimento. Senti que não caminhava só pelo mundo... reconheço-me como tecelã de outros tempos. Sigo tecendo novas tramas, buscando encontros onde diferentes experiências e saberes possam dialogar e nos ajudar a "re-entender as tramas, os fatos, os feitos" (FREIRE, 1992, p. 44).

A metáfora trama vem de Freire, no livro Pedagogia da Esperança no qual discute o termo de forma intensa. Mesmo quando "a palavra trama não está grafada, a imagem da trama é tecida com outras palavras, (...) o que está em jogo é uma vida tramada de maneira única e inconfundível. A trama não permite, de forma simplista, explicar as coisas da vida de maneira monocausal. Há muitos fatores que interagem e ao tentar descobri-los, sempre haverá alguma surpresa" (STRECK, 2001, p. 20-1).

As palavras aqui compartilhadas são frutos deste tecer a vida. Lembrando que "as palavras estão grávidas de significados existenciais. Nelas os seres humanos acumularam infindáveis experiências, positivas e negativas, experiências de busca, de encontro de certeza de perplexidade (...) Precisamos desentranhar das palavras sua riqueza escondida" (BOFF, 2001, p. 90) pois elas podem provocar novos incômodos, novos debates e criar novas possibilidades de vida.

Sigo cultivando várias palavras... dentre elas a palavra ternura. 
Ensino, Saúde e Ambiente - v. 14 n. esp. (2021): Dossiê Paulo Freire para além dos 100 anos: construir utopias, transformar a realidade, p. 79-94.

As Epistemologias Freireanas

\title{
2. EDUCAÇÃO POPULAR UM MODO DE CULTIVAR A TERNURA
}

\author{
Quem me chamou? \\ Quem vai querer voltar pro ninho? \\ Redescobrir seu lugar? \\ Pra retornar e enfrentar o dia a dia, \\ Reaprender a sonhar \\ Você verá que é mesmo assim \\ Que a história não tem fim \\ Continua sempre que você responde sim \\ À sua imaginação \\ À arte de sorrir cada vez que o mundo diz não \\ (Guilherme Arantes/Jon Lucien - Brincar de viver)
}

No tempo fraturado que vivemos a banalização da morte a ausência de uma política pública que possa garantir o direito à vida, tem tornado a travessia da pandemia algo mais pavoroso. Nos assusta saber que uma mentalidade doente que está dominando o mundo (KRENAK, 2020). E aqui no Brasil ela ganha destaque. Acompanhamos impactades uma avalanche de acontecimentos em que o tosco, o vulgar, o rude, o grosseiro, salpicado de maldade, racismo, fascismo, homofobia se espalham como um veneno.

Atravessando um cenário sombrio da história mesmo com toda cautela e cuidado que este período requer, muitas pessoas estão adoecendo, passando por um estado de enfraquecimento da potência do agir, sofrem uma espécie de intoxicação de um veneno que pode a qualquer momento vir a se espalhar e contaminar tudo. Sueli Rolnik (2003) nos fala de um "corpo vibrátil" em coma, à beira de um colapso. Não tem sido fácil viver, mas é preciso lembrar que tudo isso é vida e não morte e que a história não chegou ao final.

Krenak (2020) nos diz que este momento que atravessamos é tempo de aprendizagem. É como se a mãe natureza estivesse nos dizendo: Filho, silêncio, preste atenção!!! A terra está falando para a humanidade. E ela é tão maravilhosa que não dá uma ordem. Simplesmente está pedindo: "Silêncio, prestem atenção". Aqui estamos, em silêncio... pensando, prestando atenção no que nos passa, nos acontece, procurando aprender com a experiência a produzir sentidos para o viver. Debruçamo-nos sobre o tecer outros modos de vida que nos possibilite o direito à ternura.

Não, não pretendemos - como disse também Thiago de Mello em seus Estatutos do Homem - abandonar a palavra ternura do pântano enganoso das bocas, pois 
Ensino, Saúde e Ambiente - v. 14 n. esp. (2021): Dossiê Paulo Freire para além dos 100 anos: construir utopias, transformar a realidade, p. 79-94.

\section{As Epistemologias Freireanas}

queremos, ao contrário, fazer dela algo vivo, como um fogo ou um rio, ou como a semente de trigo. (RESTREPO, 2001, p. 8).

Ao relermos Freire a partir das "marcas" (ROLNIK, 1993), vamos como um fogo, um rio ou uma semente de trigo. Procuramos encontrar saídas onde não tem porta, como disse um camponês no texto de Pedro Benjamim Garcia (1986), vivemos o deslocamento do pensar e do agir. Um pensamento com o corpo implicado forçando uma torção no viver, de modo a desobstruir as nascentes do devir em nós.

Neste tempo de distanciamento, isolamento, escutamos um pensamento que vem das entranhas, que nos convoca à teimosia, à rebeldia a reinventarmo-nos no mundo, a dizer não a toda forma de servidão, aos modos de vidas tristes, à vida sem graça.

Pensar a educação a partir do princípio do cuidado em busca da ternura é uma opção política, um movimento de constituição de novos territórios existenciais, é uma tentativa de forçar um desvio no rumo da história em busca de práticas mais coletivas, comunitárias e populares. "Para encontrar saída onde não tem porta é necessário não só a imaginação, mas coragem de bater a cabeça na parede antes de encontrar a saída” (GARCIA, 1986). É aprender a roçar a dimensão trágica da vida.

A meu ver as experiências de educação popular configuram-se como territórios existenciais potentes para germinação e florada da ternura, pois ela carrega consigo princípios e valores que servem como adubo orgânico, deixando a terra fértil para que o bulbo possa originar novas plantas.

Reafirmamos a urgência da pedagogia biófila de Freire, por entendermos que "ninguém caminha sem aprender a caminhar, sem aprender a fazer o caminho caminhando, sem aprender a refazer, a retocar o sonho por causa do qual a gente se pôs a caminhar" (FREIRE, 1992, p. 155).

A Educação popular apoia-se no diálogo, na problematização da realidade, na produção de um conhecimento capaz de ampliar a vida, pensa e vivencia a educação a partir do princípio do cuidado valoriza os saberes dos educandos e das educandas. Esta pratica ancorada no respeito e no cuidado abre possibilidades para que nossos mapas "cognitivos, interacionais e societais" ${ }^{3}$ sejam redesenhados.

\footnotetext{
${ }^{3}$ SANTOS, 2000, p. 41.
} 
Ensino, Saúde e Ambiente - v. 14 n. esp. (2021): Dossiê Paulo Freire para além dos 100 anos: construir utopias, transformar a realidade, p. 79-94.

\section{As Epistemologias Freireanas}

O projeto popular de educação é uma forma de resistência, re-existência! Uma revolução silenciosa (CERTEAU, 2012). Um movimento de criação, de reinvenção de "si" e do mundo. Um dizer não ao descaso e descuido com a vida humana e as outras vidas não humanas, rios, matas, animais, o mar, o ar.

A acolhida, a escuta, a solidariedade, o respeito presente nos encontros de educação popular nos atravessam, nos afetam e nos auxiliam na travessia e no desejo de tecer novas tramas, um processo de constituição de vínculos capaz de romper com a lógica do individualismo, da competição, do preconceito e inferiorização da vida. Um atravessamento que nos mobiliza a experienciar a ternura.

Experienciamos deslocamentos do modelo "Bancário de educação" (FREIRE, 1987) que atua a partir da opressão, silenciamento e inferiorização dos educandos e educandas das classes populares para uma perspectiva de "Educação como prática da liberdade" (FREIRE, 1982). O diálogo, a escuta sensível de si e do outro vai abrindo brechas e, pelas fissuras, vai passando o desejo de viver com mais alegria e charme.

O “corpo vibrátil em coma” (ROLNIK, 2003), sufocado pelas sutilezas da política de subjetivação em curso com suas normas e verdades absolutas, é convocado. Encontros respeitosos e cheios de ternura fazem com que o modo de experienciar o pensamento na educação popular seja uma experiência de hospitalidade marcado pela acolhida, leveza, um abrigo como viveram Júpiter e Hermes na casa de Filêmon e Báucis (BOFF, 2005). Com o tempo e ao seu tempo a vida homogeneizada, embrutecida, amordaçada, silenciada vai se deslocando para novos territórios existenciais... tecemos vínculos humanos, criamos suporte para o sentimento de pertencimento a uma comunidade aquilombamo-nos,

\section{TOCANDO EM FRENTE}

Ando devagar porque já tive pressa e levo esse sorriso porque já chorei demais. Hoje me sinto mais forte mais feliz quem sabe, eu só levo a certeza de que muito pouco eu sei eu nada sei.

(Almir Sater e Renato Teixeira - Tocando em frente) 
Ensino, Saúde e Ambiente - v. 14 n. esp. (2021): Dossiê Paulo Freire para além dos 100 anos: construir utopias, transformar a realidade, p. 79-94.

\title{
As Epistemologias Freireanas
}

Encontrei em Freire um companheiro de caminhada, daquele tipo sonhador, inquieto, que está sempre disposto a trilhar caminhos em busca do novo. Com ele aprendi que ao caminharmos concretizamos "sonhos possíveis".

\begin{abstract}
Nós que temos compromisso com um mundo melhor, que sentimos hoje mais do que nunca que nossos sonhos estão sendo "rasgados”, que, mais uma vez, procuremos em e com Paulo re-fazer socialmente os sonhos possíveis de transformação, pois sabemos que só aparentemente eles foram "desfeitos", pois sonhar é destino dado. Isto é, estamos irremediável e felizmente "condenados" todos e todas que se existenciaram, que se fizeram por milênios de séculos seres humanos, a sonhar. A sonhar os sonhos humanizadores. A sonhar os sonhos ético-políticos. (FREIRE.
\end{abstract} A.M.A. 2001, p. 20).

Este texto é a expressão viva da inquietude do ser humano, do nosso processo de busca permanente. É uma tentativa de encontrar respostas a tantas perguntas, ao mesmo tempo que, no próprio processo de responder as perguntas iniciais, outras já foram sendo geradas.

Busquei e continuo a buscar em Freire respostas. A ação foi virando palavra, e as palavras foram virando mundo. Fui entendendo o que Freire dizia com "palavramundo". As palavras iam e vinham, não eram apenas palavras, mas também desejos, afetos, intenções, ações, criações, reinvenções. Suas palavras se fizeram carne em mim e desde então tenho experimentado a "pedagogia da pergunta, do oprimido, dos sonhos possíveis, da autonomia, da tolerância". Sempre buscando respostas a tantas perguntas, que nascem de algumas respostas, cuidando de outras que ainda não dei conta de responder, ou sequer dei conta de saber que existem dentro de mim.

Continuo experimentando a "pedagogia da indignação" que me faz estar alerta e inquieta com as artimanhas da dominação que tentam nos capturar, fazendo com que esqueçamos das injustiças e descuidemos da vida. Permaneço indignada, porém me lanço no movimento de criação, de reinvenção, vivenciando a "pedagogia da esperança". Busco no encontro com o outro, o apoio para criarmos mundo em que seja menos difícil de amar e seguimos teimando em criar motivos para festejar.

A escrita deste texto é um grito em defesa da vida em busca da ternura. Uma possibilidade de espalhar o pensado e vivido em torno da educação popular. Um projeto educativo que parte do reconhecimento da nossa fragilidade e da necessidade de estendermos as mãos, tecermos redes e tramas. 
Ensino, Saúde e Ambiente - v. 14 n. esp. (2021): Dossiê Paulo Freire para além dos 100 anos: construir utopias, transformar a realidade, p. 79-94.

\section{As Epistemologias Freireanas}

Precisamos desacelerar, habitar outros modos de viver. Interessa-nos o movimento de criação, a vida como obra de arte, a ternura.

Reconhecendo o aspecto interminável deste texto carrego comigo o raminho azul, mais que nunca necessitamos do riso, da festa, do modo de ser escancarado do palhaço, do sublime, da alegria do modo de vida brincantes das comunidades tradicionais para "escapar ao encarceramento" dos nossos corpos.

\section{REFERÊNCIAS}

ACOSTA, A. O Bem Viver: Uma oportunidade para imaginar outros mundos. (Tradução Tadeu Breda). São Paulo: Autonomia Literária, 2016.

BARROS, M. Poesia completa. São Paulo: Leya, 2010.

BOFF, L. Saber Cuidar: Ética do humano - compaixão pela terra. 7. ed. Petrópolis: Vozes, 2001.

- Virtudes para um outro mundo possível: Hospitalidade, direção e dever de todos. Petrópolis, RJ: Vozes, 2005.

CERTEAU, Michel de. A cultura no plural. Campinas: Papirus, 2012.

DELEUZE, Gilles. conversações. São Paulo: Editora 34, 1992.

FERREIRA, Dulcinéia de Fátima; VARGA, Istvan Van Deursen. Cultura popular e processos de subjetivação: em busca de linhas de vida . Laplage em Revista (Sorocaba), $\begin{array}{lllll}\text { vol.4, n.1, jan.-abr. } & \text { 2018, } & \text { p. } & \text { 67-80. }\end{array}$ http://www.laplageemrevista.ufscar.br/index.php/lpg/article/view/437/641

FREIRE. A.M.A (org).. Pedagogia dos sonhos possíveis. São Paulo: UNESP, 2001.

FREIRE, P. Educação como prática da liberdade. 13. ed. Rio de Janeiro: Paz e Terra, 1982. Educação e mudança. 8ed. Rio de Janeiro: Paz e Terra, 1983.

. Pedagogia do Oprimido. 17. ed. Rio de Janeiro: Paz e Terra, 1987.

. Pedagogia da Esperança. Rio de Janeiro: Paz e Terra, 1992.

Pedagogia da indignação: cartas pedagógicas e outros escritos. São Paulo, Editora $\overline{\mathrm{UNESP}}, 2000$.

Política e Educação. 4. ed. São Paulo: Cortez, 2000a. 
Ensino, Saúde e Ambiente - v. 14 n. esp. (2021): Dossiê Paulo Freire para além dos 100 anos: construir utopias, transformar a realidade, p. 79-94.

\section{As Epistemologias Freireanas} $2000 \mathrm{~b}$.

. Professora sim, tia não: cartas a quem ousa ensinar. São Paulo: Olho d'Água,

GARCIA, P. B. A questão política da Educação Popular. 6.ed. São Paulo: Brasiliense, 1986.

KRENAK, Ailton. O amanhã não está à venda. São Paulo: Companhia das letras, 2020.

LINHARES, C. Paulo Freire: memórias como narrações compartilhadas. In FREIRE, A.M.A. et.al. Pedagogia da Libertação em Paulo Freire. São Paulo: UNESP, 2001.

MADURO, Otto. Mapas para festa: reflexões Latino-Americanas sobre a crise e o conhecimento. Petrópolis: Ed. Vozes, 1994.

MBEMBE, Achille. Necropolítica. São Paulo: N-1 edições, 2020.

MELLO, T. Poemas preferidos: pelo autor e seus leitores. 2.ed. Rio de Janeiro: Bertrand Brasil, 2002.

OLIVEIRA, Ana Lucia C. Aprendendo com os guaranis a resistir e sonhar com terras livres. 2020. Dissertação (Mestrado em Educação) Programa de Pós - Graduação em Educação, Departamento de Ciências Humanas e Educação. Universidade Federal de São Carlos, Sorocaba/SP, 2020.

PEREIRA, D.F.F. Paulo Freire: Uma vida como obra que permanece. Revista IberoAmericana de Estudos em Educação (UNESP UNIV ALCALÁ). v. 9, n. 2, abril/junho de 2014. (p. $247-262$ )

RESTREPO, L. C. Direito à Ternura, Petrópolis, Vozes, 2000.

ROLNIK, Sueli. Pensamento, corpo e devir. Caderno de Subjetividade, v.1 n.2:241-251. Nucleo de Estudos e Pesquisas da Subjetividade, Programa de Pós Graduados de Psicologia Clinica, PUC/SP. São Paulo, set./fev. 1993.

. "Fale com ele" ou como tratar o corpo vibrátil em coma. Conferência proferida no simpósio: Corpo, Arte e Clínica. Instituto de Psicologia, Programa de Pós-Graduação em Psicologia Social e Institucional, UFRGS, Porto Alegre, 11 mar. 2003. Disponível em: $<$ http://www.pucsp.br/nucleodesubjetividade/Textos/SUELY/falecomele.pdf $>$. Acesso em: 10 mar. 2017.

SANTOS, B. S. A crítica da razão indolente: contra o desperdício da experiência. 2.ed.São Paulo: Cortez, 2000.

. (org.) Para uma sociologia das ausências e uma sociologia das emergências. in

Conhecimento Prudente para uma Vida Decente: 'Um discurso sobre as Ciências' revisitado. São Paulo: Cortez, 2004 (p. 777 -821).

STRECK, D. R. Pedagogia no encontro de tempos: Ensaios inspirados em Paulo Freire. Petrópolis, RJ: Vozes, 2001. 
Ensino, Saúde e Ambiente - v. 14 n. esp. (2021): Dossiê Paulo Freire para além dos 100 anos: construir utopias, transformar a realidade, p. 79-94.

As Epistemologias Freireanas

\section{SOBRE A AUTORA}

\section{DULCINÉIA DE FÁTIMA FERREIRA}

Educadora popular desde os anos de 1980, Pedagoga, Metre e Doutora em Educação pela UNICAMP (Universidade Estadual de Campinas- SP). Possui Pós doutorado em cultura popular pela UFMA (Universidade Federal do Maranhão). Professora Associada II do Centro de Ciências Sociais e Departamento de Educação da UFMA. rofessora Associada da Universidade Federal do Maranhão (UFMA- Campus São Luís ). Vinculada ao Departamento de Educação II . Pós Doutorado em Cultura Popular junto à Universidade Federal do Maranhão (UFMA). Doutora e Mestre em Educação pela Universidade Estadual de Campinas (UNICAMP). Eixos temáticos: Educação, Cultura e políticas de subjetivação, Educação popular, Cultura Popular e processos educativos; Educação de Jovens e Adultos, Educação como prática da liberdade 